\title{
Scenario Analysis of Greenhouse Gases Reduction by Changing Consumer's Shopping Behavior
}

\author{
Naoki Yoshikawa ${ }^{a}{ }^{*}$, Natsumi Fujiwara ${ }^{b}$, Junko Nagata ${ }^{b}$, and Koji Amano ${ }^{a}$ \\ ${ }^{a}$ Ritsumeikan University, 1-1-1 Nojihigashi, Kusatsu Siga Pref. 525-8577, Japan \\ ${ }^{b}$ Osaka City University, 3-3-138 Sugimoto Sumiyoshi-ku, Osaka 558-8585, Japan
}

\begin{abstract}
Sustainable consumption plays an important role in the mitigation of global warming and the conservation of energy. Promoting more environmentally responsible consumer behavior, especially through open communication between stakeholders, is one way to achieve low-carbon consumption. This study evaluates the potential for reducing greenhouse gas (GHG) emissions through behavioral transformation of consumers in terms of their daily shopping habits. In this context, the behavioral transformative actions pertain to certain foods and daily necessities, and are analyzed from a life cycle assessment perspective. We developed multiple product-selection scenarios to evaluate GHG emissions related to the daily purchase of commodities. Based on the life cycle assessment, we estimated the GHG emissions that result from the production and distribution of these commodities, pertaining to both the current product selection and to a possibly improved selection. The results of our study show that because of seasonal consumption patterns and energy conversion, there is a substantial potential to reduce GHG emissions resulting from outof-season produce cultivation. The GHG reduction potential is not high for each individual commodity because diverse commodities are needed on a daily basis. However, various actions in combination could have substantial potential for reducing emissions.
\end{abstract}

Keywords: Final consumption-based $\mathrm{CO}_{2}$ emissions; Change in consumption behavior; Food; Scenario-based approach

\section{Introduction}

Sustainable lifestyles play an important role in the mitigation of global warming [1]. UNEP [2] reports that the consumption of goods by households is responsible for the majority of global greenhouse gas (GHG) emissions; the most important consumption activities relate to purchasing food, mobility/transport, and housing. Emissions of carbon dioxide $\left(\mathrm{CO}_{2}\right)$, a major GHG, through household consumption activities result from fossil fuel combustion. Thus, the daily shopping choices of consumers, such as food purchases, have an important effect on GHG emissions and fossil fuel consumption, and the reduction thereof in households. One way to shift consumer behavior towards greater environmental responsibility is to increase communication between all trade stakeholders: producers, retailers, and consumers [3]. Researchers working on the project Creating a Low-Carbon Production, Retail and Shopping System for Nagoya have developed a communication platform that brings together the producers, retailers, and consumers in Nagoya, Japan [4]. This project aimed to increase environmentally friendly consumer behavior by suggesting goods and lifestyle choices that would be beneficial to both the environment and the consumers.

As an example, UNY Co. Ltd., a retailer based in the Tokai region of Japan, has engaged in direct conversations with its female customers through a platform called the Researchers Club. Via this platform, the consumers and the company jointly concluded that to achieve a comfortable lifestyle for consumers, as well as a reduction of the environmental load, the following measures had to be taken simultaneously: consuming locally produced vegetables; consuming vegetables in season; choosing crops cultivated with fewer chemical fertilizers; and selecting products packaged in simple, plain containers. Furthermore, to spread these ideas among the larger consumer base, flyers, proposed by the consumers themselves (see Fig. 1), were posted at UNY-run supermarkets.

Another study indicated that in an effort to achieve environmentally friendly services and operations, companies often take a material-oriented approach, dealing only with problems such as the emissions of company-specific waste that harms the environment. These activities are usually distinct from business administration [5].

Therefore, the Researchers Club is a novel approach in which a company and its customers cooperate to achieve the mutually beneficial goals of benefiting consumers while reducing the environmental load.

However, for such suggestions to be effective, they must be very specific. Additionally, it should be possible to accurately quantify the GHG reduction potential resulting from the specific changes in consumer behavior. Shigeto et al. [6] evaluated the potential reduction of GHGs from households in Kyoto, Japan. This evaluation considered energy use, transportation use, and waste generation from the households. However, no consideration was given to GHG emissions related to shopping for household commodities.

\footnotetext{
* Corresponding author. Tel.: +81-77-599-4139; fax: +81-77-561-2667.

E-mail address: n-yoshik@fc.ritsumei.ac.jp.
} 
Some life cycle assessment (LCA) based studies have been developed to quantify the effects of product choices, such as local consumption, seasonal production [7, 8], and dietary choices [9, 10]. Researchers focused at the product-level or individual diet-level in these studies. In some studies [11, 12], GHG emissions or the energy demands resulting from organic versus conventional cultivation of some crops have been analyzed. These approaches can quantify the potential of individual purchasing decisions, but cannot, however, evaluate the effect of mass behavior change at either the regional or the country levels. Evaluating GHG emissions reductions of a broad geographic area is important in planning individual GHG emissions reductions consistent with regional/national GHG emissions reductions.

Our study evaluates the potential reduction of GHGs elicited by changes in the daily behavior of consumers. We have developed consumer behavioral transformative actions pertaining to certain foods and daily necessities. We adopted an LCA perspective to consider the GHG emissions in both the upstream and the downstream sections of the supply chain.

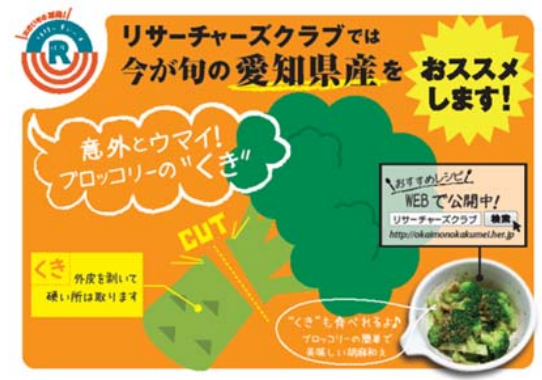

Fig.1 A consumer-designed flyer that promotes a local seasonal vegetable [4]

Table 1. Percentage of life cycle $\mathrm{CO}_{2}$ emissions in the final consumption of households [6]

\subsection{Framework}

In this study, the volume of $\mathrm{CO}_{2}$ emissions was quantified that would be reduced through the adoption of daily purchasing behavior in various scenarios. As numerous items are purchased routinely, an evaluation covering all items was problematic. Therefore, an arbitrary selection was performed for product selection scenarios that met the criteria indicated in section 2.2.

Japan was selected as the geographical scope for the evaluation, and the behavior of interest was household purchases of fresh food. The focus was placed on food products, as these are purchased frequently and the products are usually conspicuously displayed on sales floors. Furthermore, among consumer goods routinely purchased, these products contribute significantly to the life cycle emissions for $\mathrm{CO}_{2}$. Table 1 is an example of the estimated volume of $\mathrm{CO}_{2}$ emissions that derive from the purchasing behaviors of Japanese households, as based on household consumer statistics [6]. The information indicates that food consumption, including eating out, accounts for $15 \%$ of $\mathrm{CO}_{2}$ emissions in Japan. This

\begin{tabular}{|c|c|}
\hline & $\begin{array}{c}\text { Ratio } \\
\%\end{array}$ \\
\hline Food & 15 \\
\hline Housing & 1 \\
\hline Fue l, light and $w$ ater charges & 49 \\
\hline (Electric ity) & 22 \\
\hline (Gas, $m$ anufactured and $p$ ped) & 16 \\
\hline ( quefied propane) & 6 \\
\hline Kerosene) & 5 \\
\hline (0 ther fue land light) & 0 \\
\hline (W ater and sew erage charges) & 0 \\
\hline Fumiture and househo dd utensils & 2 \\
\hline $\mathrm{C}$ bthing and footw ear & 2 \\
\hline Medical care & 2 \\
\hline Transportation and com m unication & 14 \\
\hline (Gasoline) & 9 \\
\hline Education & 1 \\
\hline Culture and recreation & 5 \\
\hline 0 ther consum ption expend iture & 12 \\
\hline
\end{tabular}
percentage is second only to the energy sector, including electrical power and city gas, and is equal to that of the transportation sector, including gasoline.

The LCA methodology was adopted to evaluate the potential for GHG reductions. When looking at product selections that can contribute to a reduced environmental impact, some product features need to be considered, including commodities that reduce environmental impact in relation to production, and others that reduce environmental impact in shipment to retail outlets, the use of the product, or its disposal. Therefore, it was considered an appropriate approach to use the LCA method to perform an evaluation based on the product life cycle.

Generally, the GHG reduction potential in each scenario could be estimated related to one unit of product selected. The estimated reduction potential was subsequently multiplied by the total activity volume (purchase volume) and the resulting figure was considered the maximum reduction potential (Equation 1). 
Maximum GHG reduction potential $=\sum$ (unit reduction potential $*$ consumption quantity)

132

133

134

135

136

137

Where $i$ is the item $i$.

However, the reduction potential in Equation 1 was based on all product selections being made according to the scenario, which is not necessarily a realistic assumption. This scenario would be conceivable if the proposed product selections were significantly superior in price and quality than the conventional selections, and the conventional products that are subject to conversion from the market were eliminated, However, this would be difficult to achieve. Therefore, the GHG reduction potential described above was considered the maximum reduction potential, and we defined the feasible reduction potential, which is the expected behavior conversion rate. The feasible reduction potential is estimated by Equation 2 .

Feasible GHG reduction potential $=\sum_{i}$ (Maximum GHG reduction potential $*$ behavior conversion rate)

Farm-to-store was considered the boundary of the product life cycle for estimating the unit reduction potential since the scenario described in section 2.2 was used rather than the scenario for product use and disposal. The difference in emissions volumes before and after changing product activity selections was calculated as the unit reduction potential. The calculation method for each scenario was outlined in section 2.3.

The consumption quantity was estimated according to the Japanese household consumption statistics. The calculation was done by multiplying the purchase volume by product category per household, as indicated in the Family Income and Expenditure Survey [13], by the number of households. In order to complete the evaluation, the respective data for each prefecture was used to estimate the consumption volume at the prefectural level.

\subsection{Scenario development}

As mentioned previously, consumers purchase large numbers of diverse items daily. Although the quantification of the GHG emissions of individual products is problematic, the reliability of the estimated results of the reduction effect diminishes when the items are summarized. In this study, therefore, a detailed classification of household consumption statistics was employed. For instance, when considering vegetables, detailed classifications, such as tomato, spinach, and lettuce, were used. At this detailed level, based on data issued by public authorities, it was possible to calculate the environmental impact data of each item (the life cycle inventory (LCI)).

In this study, a product-selection scenario based on product classifications was created, which is expected to have a relatively significant potential to reduce environmental impacts. The objective of the Nagoya project [4] was also considered in selection criteria. This objective was to encourage behavioral changes by engaging in communication with consumers. Promoting open communication with the consumer being essential, items were selected in accordance with the following conditions:

- Based on prior studies, items that clearly have substantial GHG emission volumes during their life cycles.

- Items expected to have a significant GHG reduction rate, based on changes in product selection.

- Items frequently purchased.

The four scenarios discussed below are the behaviors that were selected for this study (Table 2. See details of selected food items in Table 3). They correlate to the behaviors indicated by social experiments performed in the Nagoya project.

Table 2 Actions relating to shopping behavior

\begin{tabular}{|l|l|l|}
\hline \multicolumn{1}{|c|}{ Scenario } & \multicolumn{1}{|c|}{ Commodity } & \multicolumn{1}{c|}{ Assumption } \\
\hline (a) Local production/consumption & Vegetables & $\begin{array}{l}13 \text { items; minimizing the total transportation distance } \\
\text { from farm to consumption area within Japan }\end{array}$ \\
\hline (b) Seasonal production/consumption & Vegetables & $\begin{array}{l}13 \text { items; 20\% reduction of unseasonal consumption, } \\
\text { maintaining the constant total consumption of vegetables }\end{array}$ \\
\hline $\begin{array}{l}\text { (c) Choice of products that use fewer } \\
\text { chemical fertilizers }\end{array}$ & $\begin{array}{l}\text { Rice } \\
\text { Vegetables }\end{array}$ & $\begin{array}{l}14 \text { items; } 50 \% \text { and }>90 \% \text { reduction in the use of } \\
\text { chemical fertilizers for vegetable and rice crops, } \\
\text { respectively }\end{array}$ \\
\hline (d) Reduction of food packaging & Meat & $\begin{array}{l}\text { Shifting from selling food on trays (material: PSP) to } \\
\text { food without trays (material: HDPE) }\end{array}$ \\
\hline
\end{tabular}

Table 3. Quantity of food items consumed (including processing and foodservice use) [14, 15] 


\begin{tabular}{|c|c|c|c|c|c|c|c|}
\hline \multirow{4}{*}{ Vegetables } & Cabbage & Spinach & Chinese cabbage & Welsh onion & Lettuce & Potato & Eddoe \\
\hline & 1,145 & 288 & 784 & 397 & 456 & 2,545 & 195 \\
\hline & Radish & Carrot & Onion & Tomato & Cucumber & Green pepper & Eggplant \\
\hline & 1,613 & 614 & 1,066 & 652 & 636 & 143 & 380 \\
\hline \multirow{2}{*}{ Rice } & Rice & & & & & & \\
\hline & 7,845 & & & & & & \\
\hline \multirow{2}{*}{ Meat } & Beef & Pork & Chicken & & & & \\
\hline & 711 & 1,540 & 1,336 & & & & \\
\hline
\end{tabular}

Unit: thousand tons

142

143

144

145

146

147

148

149

150

151

152

153

154

155

156

157

158

159

160

161

162

163

164

165

166

167

168

169

170

171

172

173

174

175

(a) Local production and consumption

If an effort is made to consume products cultivated locally, or to procure food from neighboring areas, the transport distance is reduced and, consequently, the environmental impact is reduced. This scenario considered the transport of food in Japan and the GHG reduction effect was calculated based on the reduced distance. In order to estimate the GHG reduction volume based on this scenario, the minimum data required would be those related to domestic transport at the prefectural level. Thirteen of the most frequently purchased vegetables were selected for the calculations, taking into account the significant contribution of transport to life cycle GHG emissions, and the data on the distribution of the products publicly available for each item.

(b) Seasonal production and consumption

Consuming large quantities of out-of-season foods inevitably means that these crops have to be cultivated during the off season, potentially causing an increase in GHG emissions For example, to cultivate summer vegetables during the winter in Japan, a greenhouse would have to be heated, probably with large amounts of heavy oil commonly used as fuel. Therefore, reducing the consumption of summer vegetables in winter could lead to a reduction of GHG emissions. In addition, the cultivation of winter vegetables during warm months is limited to the cooler regions of Japan; while many regions are suitable for the cultivation of winter crops during the cooler months, more energy is required to transport these crops to the consumer. For that reason, reducing the consumption of winter vegetables in summer would similarly contribute to a reduction in GHG emissions. Similar to scenario (a), calculations were based on 13 vegetables, for which public statistics were well established.

(c) Choice of products that use fewer chemical fertilizers

If crops cultivated with less fertilizer were selected, the volume of GHG emissions would be reduced. Relatively large amounts of energy are consumed in the production of fertilizers, particularly nitrogen fertilizers. Therefore, replacing nitrogen fertilizers with organic fertilizers, such as manure compost, could reduce GHG emissions while maintaining yields close to that achieved by conventional farming. Thirteen vegetables and rice were selected from the crops produced in Japan for the calculations. The selection was based on established statistical data and from the perspective of production volume, in which GHG emissions were expected to be high.

(d) Reduction of food packaging

If the packaging of food was reduced while still preserving food, the GHG emission volumes would also be reduced. Made from a material that utilizes few natural resources, the "leaf pack" (see Fig. 2) has been used in recent years to package food. Replacing the food trays commonly used in supermarkets with leaf packs reduces the consumption of resources and the emission of GHGs. Oil is commonly used for packaging materials, and fossil fuels are used in manufacturing. Meat was selected as the commodity in this scenario as it is frequently purchased and leaf packs are often used for packaging.

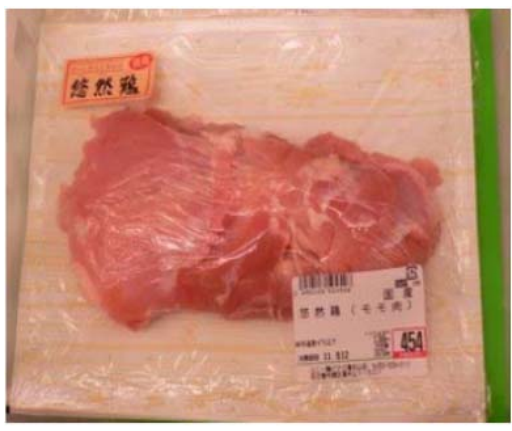

Fig.2 Leaf pack [4] 
The life cycle GHG emissions for each target item, the GHG reduction potential of each scenario, and the shopping behavior conversion ratio were quantified, as described below.

\subsubsection{Estimation of current GHG emissions}

Rice is one of the items for which lifecycle GHG emissions were estimated. The Ministry of Agriculture, Forestry, and Fisheries [16] has reported the average production cost of rice per expense item (fertilizer, fuel, pesticide, etc.), based on a survey of multiple producers. The Ministry's document was used for our calculations because the value reported the average among several producers, was considered representative of rice production in Japan, even though this value did not represent any specific agricultural technique. The production cost per expense item (specified on a weight basis for certain items) was multiplied by the intensity of GHG emissions for each expense item in order to calculate GHG emissions from the production process. The intensity of GHG emissions, based on the input-output table [17], was applied to the expense items for which only the expense amount data were available. However, for expense items for which material quantity data were also available, the IDEA [18], a Japanese database on the life cycle inventory, was used to calculate the intensity of GHG emissions. In the agricultural sector, the emission of GHGs from soil, including methane and nitrogen dioxide, should also be taken into consideration. These emissions were estimated by using the data provided in a Japanese GHG inventory report [19]. Furthermore, the transportation of food from the place of production to the place of consumption was considered. Since required detailed logistics had not been calculated for rice, the transport margin per unit yield was determined from the Japanese input-output table and multiplied by the intensity of GHG emissions [17].

The estimate of life cycle GHG emissions for major items as calculated by Yoshikawa et al. [15] was employed for vegetables, because these authors had used methods similar to those used for rice. As detailed data for each prefecture were available, the estimation for transportation was made in the following manner: It was assumed that for intraprefectural transport, trucks would be used, while the differences in the transport systems of the prefectures were taken into consideration for inter-prefectural transport. In each calculation for the latter, the distance between the prefectures was multiplied by the intensity of GHG emissions for each transport system. For food packaging, the existing lifecycle inventory data [20] were used to calculate GHG emissions per unit weight at the point of manufacture and of disposal (incineration). To estimate the consumption of packaging materials for meat, the size and capacity of commonly used trays were estimated and were multiplied by the volume of meat purchased by the Japanese household sector.

\subsubsection{Estimation of the GHG reduction potential}

(a) Local production and consumption

This scenario was specific to a linear programming problem to minimize GHG emissions, based on the estimate by Yoshikawa et al. [15]. Given the production and consumption of each item in each prefecture and the GHG emissions per unit transport volume between the prefectures, the GHG emissions were minimized within a limitation of production and consumption quantit. (Equation 3)

$$
\begin{gathered}
\min \sum_{j} \sum_{k} x_{i, j, k} \cdot c_{j, k} \\
\text { s.t. } \sum_{j} x_{i, j, k}=D_{i, k} \\
\sum_{k} x_{i, j, k}=S_{j, k}
\end{gathered}
$$

Where $x_{i, j, k}$ is the amount of transportation of item $i$ from prefecture $j$ to $k[\mathrm{t}], c_{j, k}$ is GHG emissions from transportation per 1 ton from prefecture $j$ to $k\left[\mathrm{tCO}_{2} / \mathrm{t}\right], D_{i, k}$ is the total shipment of item $i$ from prefecture $j[\mathrm{t}], S_{i, k}$ is the total demand for item $i$ in prefecture $k$.

The transportation distance between the prefectures and the ratio of the transportation mode were taken into account to estimate $c_{j, k}$ as illustrated in Equation 4.

$$
c_{j, k}=\frac{\sum_{i} \sum_{t} e_{t} d_{t, j, k} r_{t, j, k} x_{i, j, k}^{\prime}}{\sum_{i} \sum_{t} x_{i, j, k}^{\prime}}
$$

Where $x_{i, j, k}^{\prime}$ is the actual amount of transportation of item $i$ from prefecture $j$ to $k$ in base year [t], $r_{t, j, k}$ is the percentage of transportation mode $t$ in transportation between prefecture $j$ and $k[-], d_{t, j^{\prime}, k^{\prime}}$ is the transportation distance between prefecture $j$ and $k$ by using transportation mode $t[\mathrm{~km}], e_{t}$ is GHG emissions per unit amount of transportation $\left[\mathrm{t}-\mathrm{CO}_{2} / \mathrm{tkm}\right]$ 
The difference between the GHG emissions value in actual situation and this scenario (Equations 3) is the maximum GHG reduction potential.

(b) Seasonal production and consumption

The estimation used in this scenario was also based on the data supplied by Yoshikawa et al. [15]. Based on the assumption that the consumption of summer vegetables in winter and winter vegetables in summer will decline, the scenario for the shift in consumption was developed according to the following method:. First, the consumption of summer vegetables in winter (grown in greenhouses with heating) was decreased by $20 \%$, and an equal amount of each vegetable was shifted to the summer season. Since this would result in a change in the current consumption of vegetables and subsequent nutrient intake for each season, it was necessary to compensate by shifting winter vegetables in summer to the winter season. More specifically, the volume of each type of vegetable to be shifted through seasons was determined to maintain the status quo in annual consumption of each vegetable and the total consumption of vegetables in each season. Additionally, the intake of vitamins A and $\mathrm{C}$ from the target items in each season would be within a range of $5 \%$ from the current status.

The GHG reduction potential (maximum potential) is estimated by Equation 5.

$$
G H G R P_{i}=\sum_{s} \operatorname{LCGHG}_{i, s}\left(x_{i, s}-x_{i, s}^{\prime}\right)
$$

Where $G H G R P_{i}$ is the maximum GHG reduction potential of item $i, L C G H G_{i, s}$ is the unit GHG emission of item $i$ in season $s$ through all life cycle stages [t- $\mathrm{CO}_{2} \mathrm{eq} / \mathrm{t}$ ] (GHG emissions in the transport stage is assumed an average value of the base year), $x_{i, s}^{\prime}$ is the consumption quantity of item $i$ in season $s, s$ is season.

(c) Choice of products that use fewer chemical fertilizers

This scenario replaced half of the chemical fertilizer consumption with organic fertilizer. Regarding GHG emissions per item estimated in section 2.3.1, half of the emissions from chemical fertilizers were replaced with emissions from organic fertilizers. Generally, a reduction in chemical fertilizer use might cause a slight decrease in unit yield. In this study, 5\% decrease in unit yield was assumed, based on several reports [21, 22], to calculate the GHG reduction potential.

$$
G H G R P_{i}=\left(L C G H G_{i, s}-L C G H G_{i, s}^{\prime}\right) x_{i, s}^{\prime}
$$

Where $G H G R P_{i}$ is the maximum GHG reduction potential of item $i, L C G H G_{i, s}$ is the unit GHG emission of item $i$ in season $s$ through all life cycle stages by conventional cultivation[t-CO $\left.\mathrm{C}_{2} \mathrm{eq} / \mathrm{t}\right],{ }_{L C G H G_{i, s}^{\prime}}$ is the unit GHG emission of item $i$ in season $s$ through all life cycle stages by cultivation reducing chemical fertilizer[t- $\mathrm{CO}_{2} \mathrm{eq} / \mathrm{t}$ ]

(d) Reduction of food packaging

The GHG reduction effect of minimizing food packaging for meat products is estimated by Equation 7 . With regard to GHG emissions reduced per unit volume of meat purchased, the GHG reduction potential per $1 \mathrm{~kg}$ of meat purchased was calculated from an estimate per package by an existing evaluation study [20] and the packaging material consumption per unit volume of meat purchased estimated in section 2.3.1.

$$
G H G R P_{i}=w_{i}\left(L C G H G_{\text {food tray }}-L C G H G_{\text {leaf pack }}\right) x_{i}^{\prime}
$$

Where $G H G R P_{i}$ is the maximum GHG reduction potential of item $i, w$ is weight of package per unit weight of meat purchase [t-package/t-meat], $L C G H G_{\text {foodtray }}$ is the unit GHG emission of food tray through all life cycle stages [t$\mathrm{CO}_{2} \mathrm{eq} / \mathrm{t}$-package], $L C G H G_{\text {leaf pack }}$ is the unit GHG emission of leaf pak through all life cycle stages $\left[\mathrm{t}-\mathrm{CO}_{2} \mathrm{eq} / \mathrm{t}-\right.$ package]

\subsubsection{Potential for behavior conversion}

As regards the estimated behavior conversion ratio, the rate of positive response to each choice of goods in a survey, conducted via the internet for the Nagoya project [4], was regarded as the conversion ratio (Table 4). For some questions in the survey, the conversion rate was an option. For those questions, the rate of response to each was multiplied by the conversion rate to calculate the average conversion rate. 
Table 4 Conversion ratio

\begin{tabular}{|l|r|}
\hline \multicolumn{1}{|c|}{ Scenario } & Conversion ratio \\
\hline (a) Local production/consumption & $31 \%$ \\
\hline (b) Seasonal production/consumption & $32 \%$ \\
\hline (c) Choice of products that use fewer chemical fertilizers & $34 \%$ \\
\hline (d) Reduction of food packaging & $55 \%$ \\
\hline
\end{tabular}

277

278

279

280

281

282

283

284

285

286

287

288

289

290

291

292

293

294

295

296

(b)Seasonal production and consumption

Fig. 4 shows the breakdown of the GHG reduction per product (the case shifting $20 \%$ of summer vegetables). It suggests that changing the production area of winter vegetables would reduce GHG emission as well as shifting summer vegetables. The GHG reduction achieved through the 13 vegetables is expected to be $4.4 \%$.

(a) Local production and consumption

By product, a longer average transport distance does not necessarily result in a greater GHG reduction potential (Fig.3), because for these products it is difficult to change the combination of production and consumption areas, as the producing region is limited, especially in cultivating winter vegetables in summer. On the other hand, a greater reduction in GHG is expected for products cultivated in a wider range of prefectures. A reduction of $5.2 \%$ in life cycle GHG emissions related to transport is achievable for all 13 most frequently purchased vegetables.

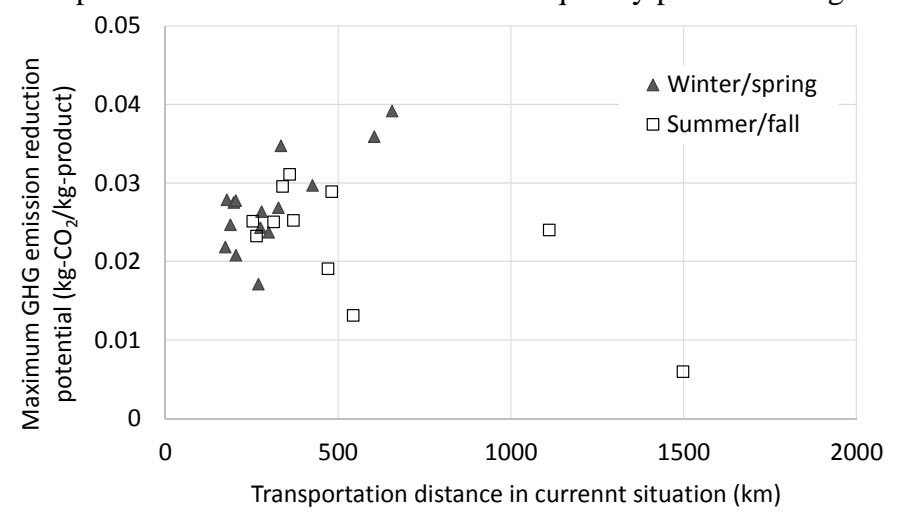

Fig.3 Relationship between transportation distance and GHG emission reduction potential in local production and consumption scenario

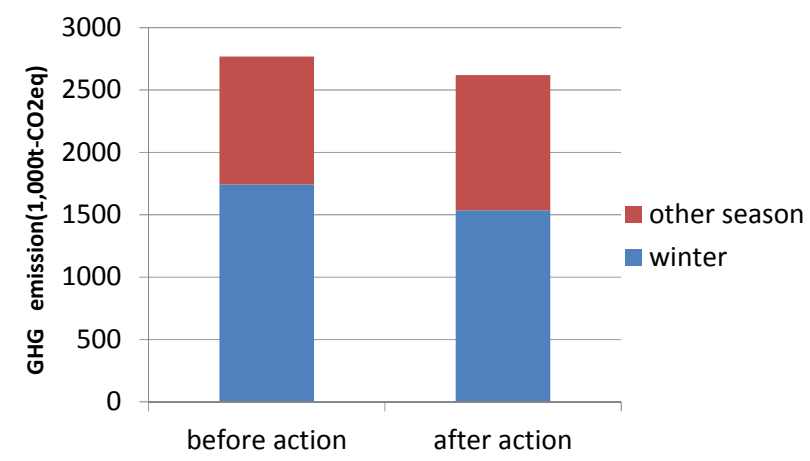

Fig.4 GHG emissions pertaining to vegetable consumption with respect to seasonal production and consumption (20\% case) 
(c) Choice of products that use fewer chemical fertilizers

The estimated results of the GHG reduction from choosing alternative products that use fewer chemical fertilizers for select crops are shown in Fig. 5. The results suggest that for crops with a lower proportion of fertilizers in the GHG emissions, the reduction would be less. For other products, including rice, spinach, and eggplant, a relatively high reduction rate is expected. The GHG reduction achieved for all subject products is estimated to be 3.1\%.

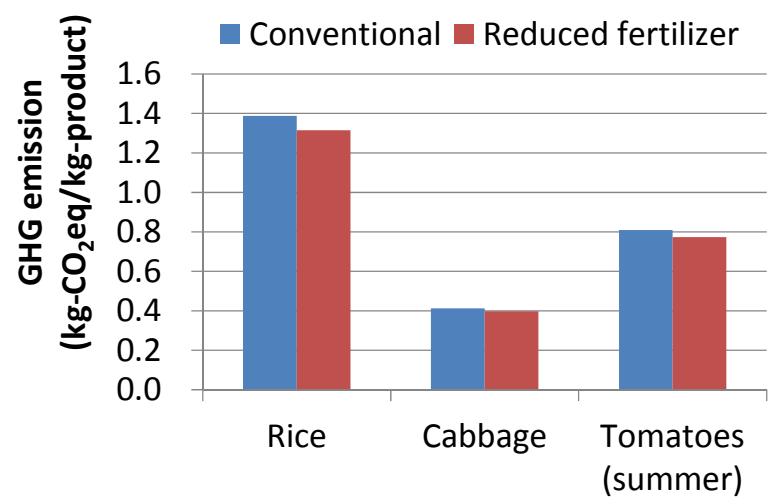

Fig.5 Unit GHG reduction potential through reduced chemical fertilizer use

(d) Reduction of food packaging

Switching food packaging to the leaf package would reduce the weight of packaging materials by approximately $80 \%$, while switching the packaging material from polyethylene foam to high-density polyethylene would reduce the GHG emissions per unit weight of meat by $0.19 \mathrm{~kg}-\mathrm{CO}_{2} / \mathrm{kg}-\mathrm{meat}$.

\subsection{GHG reduction potential}

Fig. 6 indicates a potential reduction obtained by multiplying the above consumption by the unit reduction potential estimated in Section 3.1, and a feasible reduction obtained by multiplying the above potential reduction by the behavioral conversion rate of customers. The maximum potential of seasonal production and consumption in Fig. 4, indicates the potential in 3.1(b) multiplied by five (assuming a 100\% shift in behavior). The estimated GHG reduction, with a local production and consumption execution rate of $50 \%$, is roughly the same as that of reducing the use of

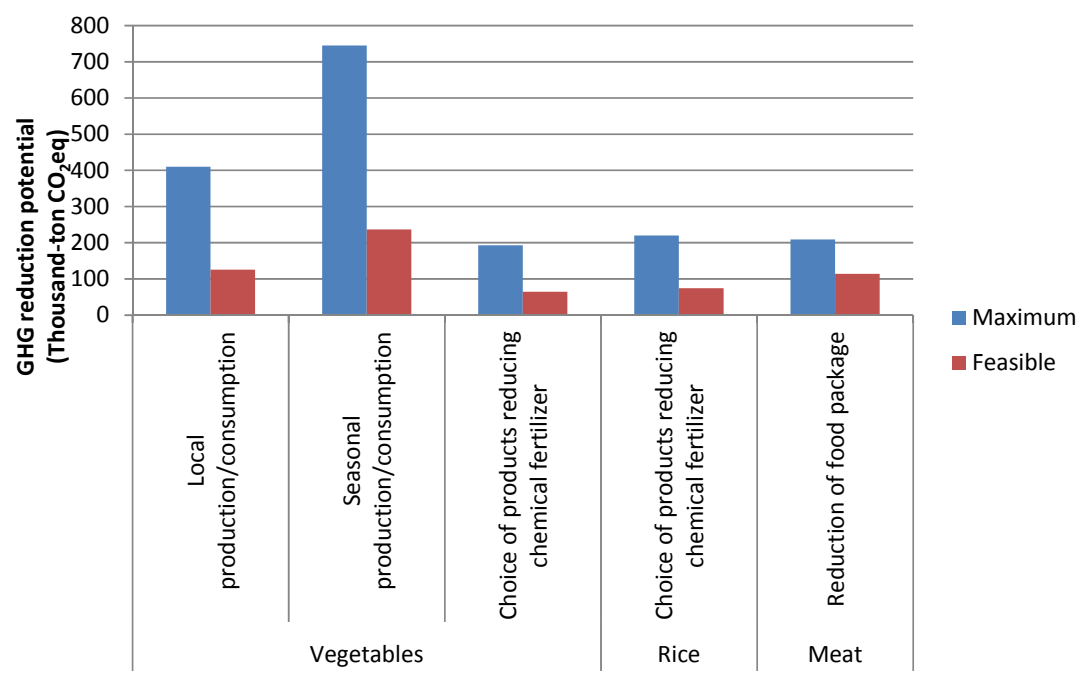

Fig.6 Maximum and feasible GHG reduction potentials through amended food-specific shopping behavior 
chemical fertilizers by $100 \%$ and a conversion rate of $100 \%$ in meat packaging material. Considering the conversion rates, the seasonal production and consumption rates have the highest potential to reduce GHG emissions.

Overall, the total maximum GHG emissions reduction potential from all scenarios is $1367 \mathrm{kt}^{-\mathrm{CO}_{2}}$ and the feasible GHG emissions reduction potential is $616 \mathrm{kt}-\mathrm{CO}_{2}$. When compared with the $\mathrm{CO}_{2}$ emissions of household consumption estimated by Shigeto et al. [6], this maximum reduced amount is equivalent to the emissions from the annual consumption of approximately 150,000 households. However, with regard to the reduction rate, we observed that actions in small numbers did not result in a substantial reduction. A feasible method to change consumer behavior to substantially reduce GHG emissions, must assess combinations of numerous actions pertaining to a large number of items and product life cycles. Here, we estimated the potential while assuming that all, or an externally determined proportion of, consumers would take action. In practice, however, to correctly model the effect of behavior changes, critical factors that influence such changes in behavior, such as price and convenience, should also be considered during implementation.

Uncertainties in the estimation should also be taken into account, to provide a robust result. Both consumer's choices and the result of LCA contain uncertainty related to data limitations, statistical variation, and assumptions. Assessing uncertainty will help show how suggestion can robustly reduce GHG emission and fossil energy consumption. In particular, a stochastic linear optimization model will be applicable to Scenario (a) for optimization under uncertain conditions.

Additionally, the GHG reduction potential of different products varies according to the country or region of origin, depending on the production and distribution environment and the prevalent food consumption patterns. To promote efficient, environmentally friendly actions using simplified estimations, both evaluation and implementation should be region-specific. The development of regionally specific scenarios and estimation methods entails shorter research time and lower costs, and is expected to enable consumers to make more precise decisions.

\section{Conclusion}

As a preliminary step to proposing changes in shopping behavior through communication between retailers and consumers, we have estimated the GHG reduction potential through behavioral changes resulting from four scenarios. The results of our study show that such changes would achieve a reduction in emissions. However, to achieve substantial emissions reductions, it is necessary to examine a larger number of possible actions. Various reduction efforts by producers and distributors would be required for each product life cycle stage, and the information provided in would have to be very specific. To promote low-carbon consumption activities, it would be necessary to further examine qualitative and quantitative emission effects and appropriate communication, using information supported by sufficient data. Robust reduction efforts are also required from all individuals and businesses in the production and consumption chain.

\section{Acknowledgements}

This study is based on the results of the JST-RISTEX R\&D program Community-Based Actions Against Global Warming and Environmental Degradation (FY2008-2013). 


\section{References}

[1] H Imura, M Okuno, T Futawatari. Study on the public attitudes and behavior towards the protection of the global environment. Environmental systems research.1993 vol.21: 170-179 [in Japanese with English abstract].

[2] UNEP. A Report of the Working Group on the Environmental Impacts of Products and Materials to the International Panel for Sustainable Resource Management: Assessing the Environmental Impacts of Consumption and Production: Priority Products and Materials. 2010.

[3] Ministry of the Environment. White Paper Quality of the Environment in Japan. 2001 [in Japanese]. https://www.env.go.jp/policy/hakusyo/hakusyo.php3?kid=213.

[4] JST Research Institute of Science and Technology for Society (RISTEX). R\&D Annual Report: Community-Based Actions against Global Warming and Environmental Degradation: Creating a Low-carbon Production, Retail and Shopping System for Nagoya. 2010 [in Japanese].

[5] C Aoki, T Aramaki, K Hanaki. Potential of use of eco-efficiency from viewpoints of various stakeholders. Environmental systems research. 2002 vol.30: 171-181 [in Japanese].

[6] S Shigeto, Y Yamagata, R Ii, M Hidaka, M Horio. An easily traceable scenario for $80 \% \mathrm{CO}_{2}$ emission reduction in Japan through the final consumption-based $\mathrm{CO}_{2}$ emission approach: A case study of Kyoto-city. Applied Energy, 2012, 90, 201-205 [retrieved 10.1016].

[7] S Payen, C Basset-Mens, S Perret. LCA of local and imported tomato: an energy and water trade-off. Journal of Cleaner Production, 2015, 87,139-148.

[8] A Carlsson-Kanyama. Food Consumption Patterns and Their Influence on Climate Change: Greenhouse Gas Emissions in the Life-Cycle of Tomatoes and Carrots Consumed in Sweden. Ambio, 1998, 27(7), 528-534.

[9] A Carlsson-Kanyama, M P Ekstrom, H Shanahan. Food and life cycle energy inputs: consequences of diet and ways to increase efficiency. Ecological Economics, 2003, 44, 293-307.

[10] J Ribal, L Fenollosa, P García-Segovia, G Clemente, N Escobar, N Sanjuán. Designing healthy, climate friendly and affordable school lunches, Proceedings of the 9th International Conference on Life Cycle Assessment in the Agri-Food Sector, 2014, $1103-1112$. http://lcafood2014.org/proceedings/LCA_Food_2014_Proceedings.pdf.

[11] C Foster, K Green, M Bleda, P Dewick, B Evans, A Flynn, J Mylan. Environmental Impacts of Food Production and Consumption: A report to the Department for Environment, Food and Rural Affairs. 2006.

[12] D Pimentel and M Pimentel. Food, Energy, and Society. Their Edition. 2008, CRC Press, Boca Raton.

[13] Statistics Bureau, Ministry of Internal Affairs and Communications: Family Income and Expenditure Survey, 2006, http://www.stat.go.jp/english/data/kakei/index.htm.

[14] Ministry of Agriculture, Forestry, and Fisheries. Statistical Yearbook of Ministry of Agriculture, Forestry, and Fisheries, 2007.

[15] N Yoshikawa, K Amano, K Shimada. Evaluation of environmental load on fruits and vegetables consumption and its reduction potential. Environmental systems research. 2007 vol.35: 499-509 [in Japanese with English abstract].

[16] Ministry of Agriculture, Forestry, and Fisheries: Statistical Survey on Farm Management and Economy, 2007. http://www.maff.go.jp/j/tokei/kouhyou/noukei/seisanhi_nousan/index.html [in Japanese].

[17] K Nansai, Y Moriguchi, S Tohno. Embodied Energy and Emission Intensity Data for Japan Using Input-Output Tables (3EID): Inventory Data for LCA. 2002.

[18] K Tahara, K Kobayashi, T Onoue, M Kanzaki, K Nakano. Development of Inventory Database (IDEA) Based on Process Analysis, Proc. of the 8th International Conference on EcoBalance, 2008.

[19] Greenhouse Gas Inventory Office of Japan. Center for global environmental research. In: National Institute for Environmental Studies, editors. National GHGs inventory report of Japan, National Institute for Environmental Studies. 2006.

[20] Ministry of Environment. Procedure for calculating reduction of environmental burdens by 3R actions. 2012. http://www.env.go.jp/press/file_view.php?serial=19747\&hou_id=15123 [in Japanese].

[21] Y Hirai, T Hinata. E Profitability and marketing strategy in environmental friendly agriculture. Hokunou. 2010 77(4), 369-375 [in Japanese].

[22] Niigata Agricultural Research Institute. Case studies of cultivation experiment of specially cultivated agricultural major vegetables. Research report of agriculture, forestry, and fisheries, $\quad$ Niigata prefecture. 2008. http://www.ari.pref.niigata.jp/nourinsui/seika08/katuyou/16/080216.html [in Japanese]. 